\title{
Board 7: Work in Progress: Approaches to Introduce Biomedical Engineer- ing Design to a Class with Diverse STEM Backgrounds
}

\section{Ms. Angela Lai, Carnegie Mellon University}

Angela is a current 5th year PhD student in the Department of Biomedical Engineering at Carnegie Mellon University. She is actively involved in mentoring undergraduate and graduate students in both the laboratory and in the classroom and promoting the field of BME to the younger generations.

\section{Ms. Elaine Soohoo, Carnegie Mellon University}

Elaine is a 5th year PhD student in the Department of Biomedical Engineering at Carnegie Mellon University and a clinical Artificial Heart Biomedical Engineer at University of Pittsburgh Medical Center. She has mentored undergraduate and masters students and is passionate about education outreach and increasing diversity in the STEM fields.

\section{Dr. Diane L Nelson, Carnegie Mellon University}

Diane Nelson is a post-doctorate in Chemical Engineering who is committed to exploring the unique properties of fluorinated materials and harnessing those properties to improve drug delivery vehicles. She has spent the last five years creating and testing her delivery system on various lung diseases, and is currently most passionate about the work she is doing to describe the process of drug deposition onto a surface. As a previous biomedical engineer turned chemical engineer, Diane has developed a unique perspective when it comes to utilizing a broad set of tools in both her research and classroom. She aspires to share her enthusiasm for biology and engineering through teaching and mentoring in the next stage of her career as faculty.

\section{Dr. Conrad M Zapanta, Carnegie Mellon University}

Conrad M. Zapanta is the Associate Department Head of Undergraduate Education and a Teaching Professor in the Department of Biomedical Engineering at Carnegie Mellon University in Pittsburgh, PA. Dr. Zapanta received his Ph.D. in Bioengineering from the Pennsylvania State University in University Park, PA, and his B.S. in Mechanical Engineering (with an option in Biomedical Engineering) from Carnegie Mellon University. Dr. Zapanta has served as a Visiting Assistant Professor of Engineering at Hope College in Holland, MI, an Adjunct Professor of Engineering at Austin Community College in Austin, TX, and an Assistant Professor of Surgery and Bioengineering at The Pennsylvania State University in Hershey, PA. He also worked for CarboMedics Inc. in Austin, TX, in the research and development of prosthetic heart valves.

Dr. Zapanta's primary teaching responsibilities are Biomedical Engineering Laboratory and Design. Additional teaching interests include medical device design education and professional issues in biomedical engineering. Dr. Zapanta's responsibilities as Associate Department head include overseeing the undergraduate curriculum and undergraduate student advising.

Dr. Zapanta's research interests are in developing medical devices to treat cardiovascular disease, focusing on the areas of cardiac assist devices and prosthetic heart valves. Dr. Zapanta is an active member in the American Society for Artificial Internal Organs, American Society of Mechanical Engineers, the American Society for Engineering Education, and the Biomedical Engineering Society. He is a reviewer for several biomedical engineering journals. Dr. Zapanta also serves as a reviewer for the National Institutes of Health (NIH), Cardiovascular Sciences Small Business Special Emphasis Panel and as an ABET Program Evaluator (PEV) for Bioengineering and Biomedical Engineering programs. 


\title{
Work-in-Progress: Approaches to Introduce Biomedical Engineering Design in a Short Summer Course
}

\begin{abstract}
Rising high school seniors from all over the country take summer college courses as a trial run for choosing potential majors before applying to colleges. In the initial offering of the summer course described in this paper, high school seniors took a six week, introductory, project-based course in biomedical engineering (BME). This introductory course incorporated both engineering design and clinical applications. Students were introduced to basic principles of BME design by exposure to the process of designing a medical device and its pathway to market. Students learned engineering design principles, hands on skills, and built a medical device prototype in a course-long project. Teams with common interests but varied technical skillsets were deliberately created to encourage discussion and collaboration. The course also included field trips and guest lecturers to demonstrate the interdisciplinary nature of BME, as well as multiple oral presentations. At the beginning and end of this initial course offering, evaluations were completed to gauge the course's effectiveness in teaching students about BME. These results demonstrate successful approaches and provide feedback for improving future introductory summer high school BME courses.
\end{abstract}

\section{Introduction}

The Summer Academy of Math and Science (SAMS) at Carnegie Mellon University was established in 2001 to offer rising high school seniors a supportive community of STEM scholars and an opportunity to pursue college level curriculum over the summer in preparation for college. SAMS students were admitted considering the following: low socioeconomic status, underrepresented ethnic minorities, first generation college-bound, and attendance of a rural or inner-city high school with historically low rates of admittance to top- tier institutions. Students were enrolled in a variety of courses including calculus, computer programming, a choice of biology, chemistry or physics, and an elective, such as the Biomedical Engineering (BME) course described here. This was the first year a Biomedical Engineering course was taught as part of the SAMS curriculum. The goal of this BME course was to capture the broad field of BME by teaching the basic principles of BME design with a focus on clinical applications. This course also helped students develop interpersonal skills such as teamwork, collaboration, and delegation of work which are important in engineering.

\section{Methods}

This BME course centered around a course-long project to develop a medical device prototype and to understand its pathway to market. Instead of guiding the students through a prescribed plan from beginning to end, the students were given multiple avenues to explore their own design ideas for creating a medical device. Due to the short timeline of the summer course, multiple approaches to increase engagement and learning were used. First, students were placed into teams of three students based on interests and skills. There were three teams total and each team worked on a different project. Second, students were introduced to design concepts and research strategies through lecture and subsequent hands-on lessons involving ideation or application. Third, to engage and motivate students, the course was structured as a competition 
for receiving investments, with each team acting as a medical device company. The course culminated in oral presentations of their product, which gave students the opportunity to show off their project and share what they developed, researched, and learned.

\subsection{Team Formation}

Teams were formed based on individual student surveys in order to diversify the skill sets of each team. The survey included questions on the students' familiarity with BME topics and their interests in types of projects. The questions included the following:

1. How much experience do you have in the following topics: Medical Device Design, Cardiovascular Biology, Electric Circuits, Coding, Computer Aided Design (Scale 0-5, with 0 being the least comfortable, and 5 being very comfortable)

2. What do you hope to know after taking this course?

3. Is there a specific kind of project you would be interested in?

Using the results of this survey, students were deliberately placed into teams based on common interests in BME with varying technical skill sets. This served to maximize interest and team dynamics. Each team targeted a different project: (1) a below-the-elbow prosthetic hand to aid patients missing a limb to grasp objects; (2) a drug delivery patch for the drug Naloxone to aid recovering addicts; and (3) a pill dispensing device for patients that have multiple prescriptions that require different dosage schedules.

\subsection{Curriculum - Lecture and Workshop}

Teams were guided through the BME design process as outlined in Biodesign by Yock et al. in a series of lectures and interactive workshops [1]. The complete schedule is in Appendix 5.1. Lectures focused on the following topics: needs statement refinement and ideation, background research, market analysis, and potential regulatory paths for each team's device. Workshops were allocated for team discussions and group work. Guest lecturers and a field trip to a local medical device start-up company were incorporated to illustrate real-life applications of the concepts presented in class. At several points in the 6-week course, students were asked to reflect on the talks or activities to evaluate what they knew before, what they learned, what they found interesting, and what they hoped to learn next [2]. This process of self-reflection and evaluation not only helped students identify topics they had learned but also determined what they wanted to continue studying. These reflections also helped instructors identify how to improve the lessons and better explain the theory to the students. Assessments included group written assignments for sections such as needs statement refinement and market analysis. The teams were also evaluated on oral presentations and the creation of a completed prototype.

\subsection{Hands-On Learning and Application of Ideas Learned}

The teams visited the university's makerspace, where they learned how to use different software and tools, such as Solidworks, Corel, and 3D printer programs. First, students learned in a oneto-one setting with an instructor and then applied these skills to their own prototype. Teams then worked to refine the prototype based on feedback from classmates and the instructors.

By structuring the classes with lectures followed by interactive workshops, students were able to immediately reinforce the lessons learned in the lecture with hands-on work time. The open 
prototyping workshops also allowed students to put into practice the skills they previously learned. Some teams used this time to learn skills independently, such as using an Arduino UNO.

\subsection{Oral Presentations}

Due to the inherently collaborative nature of the design process and presentation of the final product, communication by each student is essential. It is imperative to build engineering communications skills and present work that was completed to the public. Thus, the course culminated in a series of group oral presentations where teams pitched their ideas for a medical device in front of multiple audiences, including members of faculty and staff from multiple departments, other SAMS students, and family.

\section{Results and Discussion}

Three teams successfully completed the BME summer course by constructing a medical device prototype and conducting a final oral presentation. The final prototype and presentation were graded using a rubric (Appendix 5.2) by a panel of STEM faculty at Carnegie Mellon University.

After the course, students were asked to evaluate the course and instructors in an anonymous survey conducted by the SAMS program. The ratings were conducted on a scale of $1-5$, with 1 meaning "not at all" and 5 meaning "excellent". Representative comments are shown below in Table 1, with the complete evaluation presented in Appendix 5.3.

Table 1. An excerpt of survey questions and responses by students, taken at the end of the course.

\begin{tabular}{|l|l|l|}
\hline Survey Question & $\begin{array}{l}\text { Numerical } \\
\text { Rating out of 5 }\end{array}$ & Notes from Students \\
\hline $\begin{array}{l}\text { Did the Instructor } \\
\text { stimulate critical or } \\
\text { creative thinking about } \\
\text { the Project? }\end{array}$ & 4.6 & $\begin{array}{l}\text { - } \\
\text { - } \begin{array}{l}\text { The brainstorming methods were useful. } \\
\text { - They really did stimulate creative thinking. } \\
\text { All of the instructors presented a problem and has us } \\
\text { come up with a feasible solution which allowed for } \\
\text { creativity and innovation. }\end{array}\end{array}$ \\
\hline $\begin{array}{l}\text { Did the activities } \\
\text { enhance the learning } \\
\text { experience? }\end{array}$ & 4.2 & $\begin{array}{l}\text { Loved the trip to A-Lung. } \\
\text { Yes, we went to A-Lung and we saw how hard it is for } \\
\text { start-ups to get approval from FDA regulations. }\end{array}$ \\
\hline $\begin{array}{l}\text { How would you rate the } \\
\text { overall quality of this } \\
\text { Project? }\end{array}$ & 4.4 & $\begin{array}{l}\text { I really loved my project. I think this is the best, honestly. } \\
\text { We got to experience everything from wet labs to 3-D } \\
\text { printing to witnessing a succesful start-up, we really got } \\
\text { to experience a broad aspect of BME in general. } \\
\text { Rate it as very good. I learned so much from the } \\
\text { innovtion process from trial and error. }\end{array}$ \\
\hline
\end{tabular}

Feedback from individual students indicated that the workshops gave freedom and time to students to direct their own design and apply the concepts learned in a lecture. The class was successful in introducing the broad field of BME in a short summer course and motivated students to consider pursuing STEM majors in college. Data on the alumni and their chosen college are still being collected and will be presented in the final poster and conclusion.

These results demonstrate that by the end of the course students were invested in the product they had designed from scratch, had seen real world applications, and learned about the field of BME. In the future, the course content can be adjusted to incorporate guest lecturers, visits to companies, and workshops that are more relevant to specific student projects. 


\section{References}

[1] Zenios, S. A., Makower, J., \& Yock, P. G. (2010). Biodesign: The process of innovating medical technologies. Cambridge: Cambridge University Press.

[2] Andrade, Heidi, and Anna Valtcheva. "Promoting Learning and Achievement Through SelfAssessment." Theory Into Practice, vol. 48, no. 1, 2009, pp. 12-19., doi:10.1080/00405840802577544. 


\section{Appendix}

\subsection{Simplified Course Schedule}

SAMS Biomedical Engineering Applications Course

Schedule

Deliverable

\begin{tabular}{|c|c|c|}
\hline $7 / 5 / 2018$ & Introduction to BME & Class survey on skill sets and interests \\
\hline $7 / 6 / 2018$ & $\begin{array}{l}\text { Lecture: Medical Devices and the FDA and } \\
\text { Laboratory Time: Tissue Engineering }\end{array}$ & \\
\hline $7 / 11 / 2018$ & $\begin{array}{l}\text { Lecture: Innovation and finding Needs - } \\
\text { Introducing Teams, Team Building Exercise }\end{array}$ & Establish Needs Statement \\
\hline $7 / 12 / 2018$ & Lecture: Market Analysis in the Computer Lab & Market Analysis Worksheet \\
\hline $7 / 13 / 2018$ & $\begin{array}{l}\text { Workshop: Makerspace Day - Laser Cutting } \\
\text { and 3D printing introduction }\end{array}$ & Laser cut keychain with Team name and logo \\
\hline $7 / 18 / 2018$ & Field Trip: Start-up Alung Technologies & \\
\hline $7 / 19 / 2018$ & Workshop: Prototyping & \\
\hline $7 / 20 / 2018$ & Workshop: CAD Day - Solidworks & CAD file of R2D2-simple shapes \\
\hline $7 / 25 / 2018$ & Workshop: Solidworks in the Computer Lab & Bill of Materials \\
\hline $7 / 26 / 2018$ & Workshop: Makerspace and Prototype & \\
\hline $7 / 27 / 2018$ & Workshop: Makerspace and Prototype & Completed CAD model for 3D printer \\
\hline $8 / 1 / 2018$ & Workshop: Presentation guidelines & \\
\hline $8 / 2 / 2018$ & Lecture: Failure Analysis & FMEA Worksheet \\
\hline $8 / 3 / 2018$ & Guest Speaker: Bayer - Randy Lee & First Draft Presentation \\
\hline $8 / 8 / 2018$ & Oral Presentation to Faculty Panel & \\
\hline $8 / 9 / 2018$ & $\begin{array}{l}\text { Workshop day: Use comments and feedback } \\
\text { from faculty panel to improve presentation }\end{array}$ & Class survey, Final Presentation Powerpoint \\
\hline $8 / 10 / 2018$ & Oral Presentation in SAMS Symposium & \\
\hline
\end{tabular}




\subsection{Final Oral Presentation Score}

\begin{tabular}{|c|c|c|c|c|}
\hline \multicolumn{2}{|l|}{ Investment Criteria } & \multicolumn{3}{|c|}{ Score: $0=$ low score and $5=$ high score } \\
\hline Criteria & Description & Team 1 & Team 2 & Team 3 \\
\hline Problem or Need & $\begin{array}{l}\text { Problem/ Is the need } \\
\text { defined? Sustainable } \\
\text { challenges? }\end{array}$ & $5 \pm 0.0$ & $4.6 \pm 0.5$ & $3 \pm 0.8$ \\
\hline Target Market & $\begin{array}{l}\text { Clearly defined users? } \\
\text { Stakeholders? Target } \\
\text { Niche? }\end{array}$ & $4.3 \pm 0.5$ & $5 \pm 0.0$ & $4.3 \pm 0.5$ \\
\hline Current Market & $\begin{array}{l}\text { Who are the current } \\
\text { competitors? What are } \\
\text { their weaknesses? }\end{array}$ & $3 \pm 0.0$ & $3.7 \pm 0.5$ & $3 \pm 0.0$ \\
\hline Solution & $\begin{array}{l}\text { Is the idea novel? Does } \\
\text { it work better faster or } \\
\text { is cheaper than the } \\
\text { competition? }\end{array}$ & $3.3 \pm 1.7$ & $3.2 \pm 0.8$ & $2.7 \pm 0.5$ \\
\hline Future Plans & $\begin{array}{l}\text { Are the plans to move } \\
\text { forward logical and } \\
\text { feasible? FDA path? }\end{array}$ & $3.3 \pm 0.5$ & $2.3 \pm 0.5$ & $2.6 \pm 0.9$ \\
\hline \multicolumn{2}{|l|}{ Total Score } & 19 & 18.8 & 15.7 \\
\hline
\end{tabular}




\subsection{Course Evaluation Completed by Students}

\section{PROJECT LEADER EVALUATION}

(To be completed by students)

Project Title: Biomedical Engineering Applications Project

Rating Scale

Project Leader: [RETRACTED]

1 Poor

TA(s): N/A

2 Fair

3 Average

4 Good

Please complete this Summer Academy Project evaluation.

5 Excellent

\section{EVALUATION QUESTIONS RESPONSE}

Please note: the student responses are compiled from individual reports. Comments presented below are a compilation of the entire class feedback. The number score is an average of the class total based on the rating scale above. There were 9 students in your project.

1. Did the Project Instructor state clearly the goals of the Project? 4.7

2. Was the Project well planned?

3. Did the Project Instructor state clearly the criteria for student evaluation?

4. Did the Project Instructor provide adequate feedback concerning student performance?

5. Did the Project Instructor respond to questions adequately?

6. Did the Project Instructor show concern for the needs of individual students?

7. Did the Project Instructor communicate clearly and effectively?

The leaders explained what to expect in class and always give overviews of future events. Some things regarding our group project felt rushed and weren't explained/communicated. They really did. They explained what they have done in the past and they answered questions he has regarding BME. Yes through emails.

8. Did the Instructor present Project material and activities at an appropriate

level of difficulty?

Yes, learning Solidworks has been interesting but challenging. Yes, it was easy to comprehend concepts of BME. We started out with clay then 3-D printing and actual models.

9. Did the Instructor stimulate critical or creative thinking about the Project? 
The leaders proposed interesting project ideas to each group. The brainstorming methods were useful. They really did stimulate creative thinking. We had activities where we would design products. All of the instructors presented a problem and has us come up with a feasible solution which allowed for creativity and innovation.

10. Was the Instructor organized and prepared for class?

Yes

11. Did the Project introduce you to engineering, science, or computer science career options?

Great speakers and presentations. Yes. Yes they did this initially.

12. Did the Project allow you to apply concepts learned to hands-on activities?

Final product produced at the end of the program. Yes. Not really, but it was not their fault. Wet Lab!

13. Did the activities (i.e., fieldtrips, slide presentations, etc.) enhance the learning experience?

Loved the trip to A-Lung. The field trips weren't that helpful and I feel like that could have been time used for work on projects. Yes, we went to A-Lung and we saw how hard it is for start-ups to get approval from FDA redulations.

14. Overall, how would you rate the Instructor's teaching?

The leaders were passionate about our learning and concerned about our well-being. Great Overall. All the instructors were amazing! I have a beter understanding of BME and all the lessons \& projects were connected and a great experience. Very well. Coming into Biomedical EngineeringI was passionate to learn but at the same time concerned because I didn't know how to code. I'm so happy to have joined because it has allowed me to foster a creative mind even further. I really enjoyed the instructor's method of teaching because it effectively incorporated hands on activities and field trips to enhance our knowledge of BME, but more could have been don eto hel with CAD. Would rate the instructor's teaching 6/10. I think the instructor did a great job of teaching. I would rte it a 9 or a 10 out of 10. I came in not knowingmuch about BME and now I feel like I have a good foundation. I would rate it a 9/10. the lecturer was insightful, interesting and at times humorous.

15. Please comment on your overall experience with the Project TA(s).

All the PhD students worked well together. I found them to be nice, helpful, relatable and easily available. The project teachers were supportive and made time in their schedule to support the project. The project TA's were very helpful. Some were very dedicated to the project. They also did an equally great job of teaching us new concepts and providing stimulating activities.

16. How would you rate the overall quality of this Project?

The project has great potential and teaches real-world applications. The quality of this project was pretty good. I really loved my project. I think this is the best, honestly. We got to experience everything from wet labs to 3-D printing to witnessing a succesful start-up, we really got to experience a broad aspect of BME in general. Rate it as very good. I learned so much fromthe innovtion process from trial and error. The project was fun but at certain points I felt lost and needed more that was not given. I would say the overall quality of the project is a $6 / 10$. I would rate this project a 10 out of 10 . This was a great project. I would recommend to anyone interested in engineering. Overall a 9/10. I love how we are given freedom in our design and construction process. 